\title{
A COMPARATIVE STUDY ON THE STRUCTURES OF CHINESE AND KOREAN COMPOUND WORDS
}

\author{
Zhai Xun'; Yoo Eun Hee ${ }^{2}$ \\ ${ }^{1}$ College of Foreign Students Education, Wuhan University \\ Wuhan 430072, Hubei, China, \\ ${ }^{2}$ College of Chinese Language and Literature, Wuhan University \\ Wuhan 430072, Hubei, China, \\ 13607119136@163.com; 550859074@qq.com
}

Received: $3^{\text {th }}$ March 2016/ Revised: $1^{\text {st }}$ April 2016/ Accepted: $16^{\text {th }}$ April 2016

How to Cite: Xun, Z., Yoo, E. H. (2016). A Comparative Study on the Structures of Chinese and Korean Compond Words. Lingua Cultura, 10(1), 7-12. http://dx.doi.org/10.21512/lc.v10i1.884

\begin{abstract}
The goal of the research was to compare the compound words in Chinese, an isolated language, and Korean, an agglutinative language. This research used library research. The researchers found that the main characteristics of the formation of Korean compound words were that the latter element was the central word. The method of word formation decided its lexical category. Moreover, most of the internal relationships of the compound words were connection and modification. While in Chinese, the endocentric compound noun decided the part of speech of the compound word, and could be the proceeding element or the latter element. Furthermore, Chinese contained no complicated morphological changes. It is concluded that Korean is a Subject-Object-Verb (SOV) language, where verb elements demonstrate a central feature of the compound verb are always a trailing part. Thus, there is no exocentric compound verb in Korean. By contrast, Chinese is a typical SVO language. When constituting the compound verbs, nouns or adjectives can function as the structural elements. Therefore, there is no permanent position for head words.
\end{abstract}

Keywords: language structure, chinese language, Korean language, compound words

\section{INTRODUCTION}

Chinese characters are regarded as an ideogram. In general, an individual Chinese character can independently convey a meaning or meanings and consequently can serve as a morpheme. Morphemes in Mandarin are mostly monosyllabic since the majority of the Chinese characters are monosyllable. Single morpheme words are words consisting of one morpheme. Naturally monosyllabic morpheme words play a dominant role in Mandarin with some rare exceptions such as 巧克力 (qiăokèli, chocolate) which comprise of three syllables. Widely different from Chinese, Korean is considered as a phonogram, and to communicate an independent meaning. Two or more syllables are occasionally necessary, which causes the pervasiveness of disyllabic or multisyllabic morpheme words in Korean.

Morphemes in Korean can be divided into two sorts: dependent morphemes and independent morphemes regarding the grammar function. Related to independent morphemes, dependent morphemes, such as roots suffix, prepositions, and connectives, cannot serve as a word on its own. Independent morphemes, such as 밥 (bap, boiled rice), 국 (guk, soup), and 김치 (gimchi, kimchi) are able to fill in a syntactical slot all by themselves. From the perspective of meaning, morphemes inhabit two types: the substantial morpheme and the formal morpheme. The substantial which is necessary to a word, also referred to as the root, represents a particular object, status, or action. The formal morpheme, adhering to the root, conveys additional meaning or grammatical meaning. To be more specific, the formal morpheme can be a prefix or a suffix that helps form a word, and it can also be an auxiliary word or a word appendix that assists the word form.

A Korean compound word is a word that is composed of two bases such as 집안 (jip-an, household), 돌다리 (dol$d a-r i$, stone bridge), 작은오빠 (ja-geun-o-ppa, second elder brother) and 봄나물 (bom-namul, spring greens). While, a Korean derivative word is a word that is made up of a base and an affix such as 부채질 (bu-chae-jil, fanning), 덧버선 (deot-beo-seon, outer socks), and 덮개 (deop-gae, cover).A Chinese compound word is a word consisting of two roots. Their internal construction can be mainly sorted into five types: subject-predicate structure, verbobject structure, structure of modification, complementary structure, and combined structure. Compounds like 存款 
(cún kuăn, deposit), 马车 (mă chē, gharry) and 斗争 (dòu zhēng, fight) are typical for Chinese word combinations. Moreover, a derivative word is a composition of a root and an affix. They can be classified into "prefix+root" and “root+suffix" such as 老虎 (lăo hǔ, tiger), and 兔子 (tù $z$ Ǐ, rabbit). It is thereby evident that the compound words are opposite to the derivatives in Korean, and Chinese compounds include derivatives.

There are some related theories regarding compound word. According to Zhu (1984), lexicons in Chinese can be categorized into compound words and single morpheme words. Compound words can be divided into compound words, derived words and overlapping words. The inner structures of the compound word are largely similar to the syntactical structures, namely "subject + predicate", "predicate + object", "attribute/adverbial + head", "head + complement", and "head + head".

By this token, the head is fundamental to the formation of a word. The head can be defined both morphologically. It means the morpheme determines the part of speech, and semantic, where the morpheme indicates the principle meaning of the whole word.

In the 1980s, a sense of relationship in the compound word aroused great interest in the Chinese scholarship. New types, based on traditional subjectpredicate and juxtaposition, have been reported, such as the serial-verb structure as stated by Qin (1993), and Peng (1995). Syntactical analysis of the compound word is the mainstream. Ge (1988), to some degree following Zhu (1984), has claimed that the connection of heads in the word is consistent with the syntactical structure whose classifications are juxtaposition, "attribute + head", "head + complement ", "predicate + object", "subject + predicate", and overlapping structures.

Bloomfield (1933) makes a distinction between the endocentric and exocentric structure. In the endocentric structure, the part of speech of the compound is uniformed to its immediate constituents. While in the exocentric structure, the POS is different to its immediate constituents. In addition, Aronoff and Fudeman (2010) believes that the immediate constituents can determine the syntactical category and semantic contents of the compound word. Then the compound can be defined as an endocentric compound word. Otherwise, the compound will be defined as an exocentric compound word. Even exocentric compounds have heads from the perspective of syntax, take the word "figurehead" for instance. Its syntactical head is "head", while the semantic head is "figure" instead of "head". Therefore, the word "figurehead" is called an exocentric compound.

The term "head" is discussed more often from the levels of syntax and sometimes from morphology, can date back to Sweet (2014). Sweet (2014) refers it as "head word" rather than "head", claiming that if A belongs to B, then $\mathrm{B}$ is the head word. Compounds in Chinese and Korean predominate the lexical system. From the view of syntax, both of the constituents in a juxtaposition can be regarded as head; the modified element in the "attributive/adverbial + head" structure can be interpreted as a head word: and the verb in the "verb + object" structure can be explained as the head.

The scarceness of morphemic changes in Chinese contributes to the difficulty in word class partition based on the morphological transformation. Therefore, when identifying the word class, three criterions - morphology, syntactical position, and semantic content - should be taken into consideration. For example, the word 存款 ( cún kuăn, deposit), its internal syntactic structure can be identified as "verb + object" or "attribute + head". In this sense, it can be sorted as the verb or noun. This character can be as "the same in forms but different in structures". When it comes to the compound words in Korean, it is less complicated to determine which word class that a word belongs to. For example, it will have less difficulty in judging the word " 작은아버지 (jak-eun-a-beo-ji, father's younger brother)". It is constituted by two immediate elements - the attributive element "작은 (jak-eun, younger )" and the head "아버지 (a-beo-ji, father)" The relationship between elements in endocentric compounds can be classified into three types: juxtaposition, subordination, and combination from the number of the heads. As been discussed above, two constituents in a juxtaposition can be considered as heads. Compound words have both syntactic and lexical attributes, so investigating the semantic variation is an essential dimension when researching the meaning structure.

The analysis of the semantic structure in compounds can be benefited from the comparison between the meaning of the constituents and the meaning of the entire compound word. Furthermore, how the meaning of the constituents converts into the meaning of the entire compound word is an urgent but difficult issue, especially for the exocentric compounds. To address the issue, it is necessary to look into the semantic structure and how the semantic variation can be influenced by the semantic structure. The researchers will analyze the nominal compounds, verb compounds, and adjective compounds respectively.

\section{METHODS}

This research uses library research by comparing compound nouns in Chinese and Korean. The analysis will be divided into two parts. The first one will be regarding the compound nouns. Moreover, the second one is the reason why Chinese and Korean compounds are different.

\section{RESULTS AND DISCUSSIONS}

Analysis of the constitution of Compound Words in Chinese and Korean consists of the nominal compound, verb compound, and adjective compound. Nominal compounds consist of several types. They are "noun + noun", "verb + noun", and "adjective + noun".

The constitution of "noun+noun" in Korean can be divided into two modes. The first one is "common noun + common noun" such as "이튿날 (i-teun-nal, next day), 가시덤불 (gasi-deombul, thornbush), 소나무 (so-na$m u$, pine tree) 안팎 (an-pak, inside and outside)" and “ 까막까치(kka-mak-kka-chi, crow and magpie)", etc. The second noun in the model is the head and determines the word class. Also, the syntactic attributes of the compounds. The relation of the two common nouns is commonly connection and modification relationship. The other mode is "common noun + potential noun" or "the potential noun + common noun" such as "갈림길 (gal-lim-gil, forked road)" and “줄넘기 (julleomgi, rope jumping)", etc. As in the word "갈림길(gal-lim-gi, forked road)", "갈림 (gal-lim, forked)" is the potential noun and the " $\square$ (mieum)" is the nominal suffix (Hwang, 2001). It combines with the "길 (gil, road)" as the modification to become a compound noun.

In contrast, a morpheme in Chinese unites with 
another into a compound directly without any complicated morphological transformation, which facilitates the formation of the compound word. If a morpheme itself can act as a word, then it will be called an independent morpheme. If it is not, it will be a dependent morpheme. A pure dependent morpheme can combine to generate a compound, such as “植物 (zhi wù, plant)”, “驱逐 (qū zhú, expel)". The most frequently used formation in Chinese, which resembles that in Korean is also "common noun + common noun". Less constraint in the combination of the nouns enables new compounds to be boosted at present.

Next, it is about "verb + noun". It is possible in Korean for a verb morpheme to connect with nominal morpheme to form a nominal compound noun. The verb morpheme can be a root or work as an article. Article roots such as "-ᄂ(-nieun), -는(neun) and -ㄹ(-rieul)" function syntactically and semantically. However, the relation between the nominal compound word and the verb elements in Chinese distinguish from that in Korean. For example:

1. 날숨 (nal-sum, exhalation), 볼일 (bol-il, business), 뜬눈 (ddeun -nun, a sleepless night), 빨판 (bbalpan, sucking disc)

2. 접칼 (jeob-kal, jackknife), 덮밥 (deop-bap, bowl of rice served with toppings)

3. 跑车 (pǎo chē, race car), 流水 (liú shǔ̌, flowing water)

Example (1) contains verb article root and nominal morpheme. Compounds in example (2) consist of verb root and nominal morpheme. Those in Example (3) are made up of the verb morphemes 跑 (păo, race, and 流 (liú, flow) that modify the nominal morphemes 车 (chē, car) and 水 (shul, water). The nominal morphemes in all these cases are the head words and determine the word class and semantic content of the compound nouns.

Then in "adjective + noun", there are also two kinds of these nominal compounds. There is the articlelike adjective morpheme + nominal morpheme, which is consistent with the Korean grammatical rule. Then there is the adjective suffix + nominal morpheme, which is against the typical Korean grammatical rule. Only -으 (eu), and - ᄂ (nieun) can be employed to signify the word class of the adjective and collocate with the nouns. In this case, the nominal morphemes play the role of the head and determine the word class and meaning of the compound, since the adjective morphemes are qualifiers. That is the same case with most Chinese compounds of this construction. For example:

4. 싼값 (ssan-gab, cheap price), 짠물 (jjan-mul, salt water), 큰딸 (keun-ddal, eldest daughter), 큰소리 (Keun-So-ri, a large voice)

5. 동글붓 (dong-geul-but, a dull-tipped brush), 늦봄 (neut-bom, late spring), 늦더위 (neut-deo-wi, late summer heat)

6. 黑板 (hēi băn, blackboard), 「笛 (cháng dí, flute), 繁 星 (fán xīng, myriads of stars)

Case (4) sees the article-like adjective morpheme " 싼 (cheap, ssan)" + nominal morpheme “값 (gab, price)". While, examples in Case (5) consist of the adjective root "동글 (dong-geul, dull-tipped)" + nominal morpheme "붓 (but, brush)". Those in Case (6) comprise of adjective "黑 (hēi, black), 长 (cháng), 繁 (fán)” + noun “板 (băn, board), 笛 $(d i)$, 星 (xing)". To sum up, the nominal morphemes modified by the adjective morphemes are the central/head morpheme and the part of speech of the compound nouns keeping correspondent with the nominal morpheme.

In "adverb + noun", both in Korean and Chinese can an adverb combining with a noun to form a compound. The difference lies in the fact that it is less frequent in Chinese. The adverbs that apply to this type of compounds in the Korean maintain two styles: common adverbs and symbolic adverbs, in which the latter adverbs cannot be found in Chinese. Therefore, there are two structures: "common adverb + noun" and "symbolic adverb + noun". What should be paid attention to is that the adverb does not modify the noun directly but modifies a deeply hidden verb. For example:

7. 지레김치 (ji-le-gim-chi, kimchi), 막일 (mak-li, physical labor), 살짝곰보 (sal-jjak-gombo, a slightly pockmarked), 척척박사 (cheok-cheok-baksa, a knowledgeable person)

8. 悄悄话 (qiāo qiāohuà, whisper), 不轨 (bù guĭ, against the law)

As in case (7), “지레 (ji-le)" is an adverbial morpheme. It means "in advance". It indirectly modifies the noun "김치 (gim-chi)". So the compound noun " 지레김치 (ji-le -gim-chi)" is interpreted as "kimchi made before winter”. “悄悄话 (qiāo qiāohuà)” or "words spoken secretly" in case (8) is the contraction of the phrase “悄 悄说的话 (Strictly speaking)”. What “悄悄 (qiāo qiāo, secretly)" modifies is the omitted verb "说 (shuō, said)", even though roughly speaking, it seems that the adverb (secretly) modifies the noun (words).

Verb compounds will be analyzed too. There are two approaches to fabricating verb compounds, namely, "verb + verb" and "adjective + verb" when investigating the structure of the verb compound words in Korean. Specific examples will be provided in the following passage to give an insight into its morphological features.

On the syntactic level, when two verbs (verb morpheme + verb morpheme) are juxtaposed, the prior verb will be deprived of the suffix and added "고", "-아 (a)/ 어 (eo)". "고" designates that the action of the first verb happens before the action of the second one. "아 $(a) /$ 어" shows clearly the first verb is subject to the second one. However, on the lexical level, the rule is infringed. When two verb morphemes are joined to a compound, suffixes such as "고" and "-아 $(a)$ / 어 (eo)" is imitable. What should be pointed out is that even the suffixes are omitted that the relation between the two verb morphemes is not obliterated. Accompanying the omission of the suffix, it is the omission of the syllable. For instance:

9. 듣보다 (deut-bo-da, look for), 싸매다 (ssa-mae-da, bind up), 붙잡다 (but-jab-da, grasp ), 보살피다 (bosal-pi-da, take care of)

10. 꿰매다 (kkwe-mae-da, stitch), 따먹다(tta.meok. $d a$, pick), 뛰놀다 (ttwi-nol-da, to romp, to frisk), 매달다 (mae-dal-da, suspend)

In cases (9), what word is omitted is 고 (go). “ 듣보다 (deut-bo-da, look for)" or returning to its original 
form is "듣고보다 (deut-kko-bo-da, hear and see)". Both two verb morphemes can be seen as heads due to their juxtaposition. As in case (10), -어 (eo) is an ellipsis. The second verb which is modified by the first verb determinates factor when understanding the meaning of the compound. As in "꿰매다 (kkwe-mae-da, stitch)", 매다 (mae-da, fasten) is the focus and 꿰다 (kkwe-da, thread) gives some additional information to limit the extension of "매다 (mae$d a$, fasten)". Given the discrimination of their contribution to the meaning of the compound, they cannot be inverted to produce such a compound word as "매꿰다 (mae-kkwe$d a)$ ". In Chinese, verb compounds consisting of two verb morphemes are the most common. Their relationship can be juxtaposition or subordination. However, it is hard to identify the morphological central/head word in Korean.

Next, it is adjective morpheme + verb morpheme. In the situation, the verb morpheme is modified by the adjective morpheme which acts as an adverb. Thus, there is no doubt that the verb morpheme is the head in the whole compound. For example:

11. 무르익다 (mu-reu-ik-da, ripen), 같지다 (kat-ji-da, wrestling a draw), 잗다듬다 (jat-da-deum-da, nip off neatly), 설익다 (seol-ik-da, half-cooked)

12. 哀求 (āi qiú, implore), 残留 (cán líu, residue), 轻视 (qīng shi, despise), 满载 (măn zài, carry a full load)

As in example (11), 무르익다 (mu-reu-ik-da, ripen), when coming back to its original pattern, is the 무르 ( $m u$ reu) (adjective root) + 게 (-ge) (connective suffix) + 익다 $(i k-d a)$ (verb). The connective suffix "게 (-ge)" is left out to form a compound. So, it seems that the verb is directly modified by the adjective. As in the case 12, “哀求 $(\bar{a} i$ qiú, implore)", the verb “求 (qiú)" acts as the head and the adjective “哀 $(\bar{a} i)$ " acts as the adverb.

In Korean adjective compound adj, there are three major composition methods: "noun + adjective", "adjective + adjective" and "adverb + adjective" to form an adjective compound word. The adjective in the three methods is without any doubt the central word and determines the part of speech of the compound.

There are two types of "adjective + noun" compounds. The first one is the former noun functions as subject, forming verb-object structure with latter adjective serving as an object. The second one is the former noun functions as an adverb, modifying latter adjective (Ham, 2007). In Chinese, these two types of compound words also exist.

13. 맛없다 (mat-eop-da, not tasty), 버릇 없다 (beoreut-eop-da, misbehaved), 철없다 cheor-eop-da, immature), 힘세다 (him-se-da, strong)

14. 남부끄럽다 (nam-bu-ke-reb-da, shabby), 손 쉽다 (son-ship-da, flexible), 남다르다 (nam-da-reu-da, unique)

15. 面熟 (face/look familiar), 年轻 (age, young), 耳熟 (ear/sound familiar), 心酸 (heart sad/broken)

16. 雪白 (snow, white), 草绿 (grass, green), 笔直 (pen, straight), 冰冷 (ice, cold)

In case (13), the central word of "not tasty" is the latter adjective, it is part of speech determining the compound. Case (14) sees former noun functioning as a verb and modifying the latter adjective which is the central word.
So, these phrases are adjective compound words. As in case (15), "face familiar" belongs to subject-predicate (S-V) structure, and the latter word is part of speech determining this compound. As to "snow white" in case (16), the former noun functions as modifiers for the latter adjectives.

In Korean, "adjective + adjective" compound words omit the connective suffix "-고 $(-g o)$ ", combining it to develop non-syntactic compound words. In Chinese, most compound adjectives belong to the "adjective + adjective" type. The relationship between the structural elements of compound adjectives includes two types: one is the connection, the other is the modification. Connection means all the structural elements of compound adjectives are considered as central words. Modification means only the latter adjectives are considered as central words, which have great influence on compound words in part of speech. That applies to Chinese as well as to Korean. Here are some examples:

\section{7. 굳세다 (gut-se-da, strong) \\ 18. 짙푸르다 (jit-pu-reu-dadark, blue) \\ 19. 干净 ( $g \bar{a} n$ jìng, clean clear), 轻松 (qīng song, light easy), 快乐 (kuài lè, joyous happy), 艰难 (tough hard)}

20. 狂热 (kuáng rè, crazy enthusiastic), 早熟 (zăo shú, early mature), 鲜红 (xiān hóng, bright red)

The "strong" in Case (17) can be extended to "hard and powerful", which is called a connective relationship. This structure is also applied to compound nouns and compound verbs. The latter words are adjectives, which determine the compound words in the part of speech. In Case (18), "dark blue" can be interpreted as "dark blue color". The former adjectives function as the adverb by modifying the latter adjective. As to "joyous happy" in Case (19), the latter adjective can be considered as the central word, and the relationship between the two structural words is a connection. As in the last examples, "bright red" can be interpreted as "bright red color", with the former adjective functions as adverb, modifying the latter adjective which is the central word of this compound word. The relationship between the two structural words is the modification.

In this type of compound adjectives, former adjectives function as the adverb by modifying latter adjectives (Adverb + Adjective). The relationship between the two structural words is the modification. Just like compound verbs, verbs will be modified by adverbs when a word is formed. There are fewer compound words like this in Chinese.

\section{1. 다시 없다 (da-shi-eop-da, no more) \\ 22. 不安 (bù ān, not calm)}

In the case of "no more", it is not yet conclusive whether the latter word "없다 (eop-da more)" is an adverb or adjective. Here the researchers consider "다시 (없다)" da-shi (eop-da) as an adjective, modified by the former adverb "no". The latter adjective is the central word, which determines the compound word in the part of speech. That is the same with the Chinese example “不安”, where the adverb “不 (bù, not)" modifies the adjective “安 (ān, calm)”.

The reason of differences between Chinese and Korean compounds is as follows most of "noun-noun", "verb-verb", "adjective-adjective" compound words are 
combined by words of the same class. They exist both in Chinese and Korean. From the perspective of word formation, it is the easiest approach for words of classes to be integrated. However, the compound words which reflect the word order difference between English and Chinese also exist. Korean is a Subject-Object-Verb (SOV) language, where verb elements demonstrate a central feature of the compound verb are always a trailing part.

For that reason, there is no exocentric compound verb in Korean. By contrast, Chinese is a typical SVO language. When constituting the compound verbs, nouns or adjectives can function as the structural elements, whether they are preceding elements or proceeding elements. So, there is no permanent position for head words. Especially in Chinese, lots of compound verbs and compound adjectives are formed as "verb-object". In this case, most central (head) words are verbs and adjectives, so the researchers can conclude that these compounds share the left-head-word structure.

Recently, there are some theories proposed on compounds words. However, how to apply these theories to the analysis of Chinese and Korean compound words is more important. The researchers can make use of the theory of central words to test the endocentric structure and exocentric structure of compound words (Shi, 2007). It applies to the morphology and semantics of both Korean and Chinese compound words. For morphology, FeaturePercolation Convention will be useful. For semantics, researchers should also take into consideration regarding the semantic relationship between structural elements and the patterns of semantic variation.

By analyzing the compound words, it finally figured out the characteristics of Korean and Chinese compound words. Firstly, in Korean, head words will be put on the end. That is because the right-head-word rule can be applied to all the Korean endocentric compound words. However, things are different in Chinese. The position of the Chinese central word is not fixed, and sometimes central words should be checked whether the former words are central words or not. This is true for endocentric compound nouns, endocentric compound verbs, and endocentric compound adjectives.

Secondly, Korean endocentric compound words can be analyzed morphologically. There is a one-to-one correspondence between structural elements. As to Chinese, the morphological structure of Chinese compound words can be known by analyzing the central word of the endocentric word structure, but the compound words will be altered into another part of speech, such as 回信 (huíxin, return letter). If the relationship between the structural words is verb-object, this compound word will be an endocentric compound verb. On the other hand, if the relationship between the structural words is a modification, this compound word will be an endocentric compound noun. As a result, the formations of isomers do exist in Chinese compound words, so there is a one-to-many relationship between structural elements in Chinese compounds.

Through the analysis of the meaning of endocentric compound words, it is known that most of the compound words in Korean and Chinese have meaningful right-centerwords. Nonetheless, the meaningful left-center-words also exist. In Chinese, there are all kinds of endocentric compound nouns, endocentric compound verbs, and endocentric compound adjectives. However, in Korean, there is no endocentric compound noun, and there are some restrictions on the formation of endocentric compound verbs like "break up", and endocentric compound adjectives like "very clever". These compound verbs or Compound adjectives are made up of basic verbs and auxiliaries.

According to the analysis of the meaning of endocentric compound words, the relationship between all the structural elements can be identified. It can be applied to both Korean and Chinese. But it cannot be defied that a certain type of compound words just exist in one language but not in another language. For example, Korean is a kind of adherent language, and in Korean, there are meaningful endocentric compound words but no exocentric compound words.

\section{CONCLUSIONS}

The conclusion indicates the similarities and differences between Korean and Chinese compound words. First, in the endocentric compound nouns in Korean, the whole category of parts of speech are usually decided by the latter noun in the structural elements. Also, the former element is related to the latter noun showing the various parts of speech of the compound. In contrast, the endocentric compounds in Chinese compound nouns are the main elements that decide the category of parts of speech, not subjective to the proceeding elements.

Second, Korean is the language whose objects go first, and the proceeding nouns modify the preceding verbs. In Korean, verbs should be used to modify nouns, and the verb stems should be followed by an article-like suffix such as - ㄴ (- nieun) -는 (neun), and - ᄅ (- rieul), etc. In addition, this verb form is set and fixed as a compound word with the "verb + noun" structure. The article form has its own grammatical function or helps to form a compound word while conveying the meaning. Compared with Korean, Chinese contains no morphological changes between components of the compound words, so the compound nouns like "verb + noun" structure have little to do with the verbs themselves.

Third, most of the compound words in Korean are "ordinary adverb + noun" and "symbolic adverb + noun". Chinese, however, generally has no such symbolic adverb, and very few compounds are "adverb + noun".

Fourth, the difference of the word order in Korean and Chinese is also analyzed. Because Korean is an SOV language with verb elements which perform the function of central words, always appear as the last elements. Thus, in Korean, there is no exocentric compound verb in any form. By contrast, Chinese is an SVO language that verbs, nouns and adjectives can also be used to form compound verbs, whether they serve as the preceding or proceeding elements. In other words, there is no fixed position for the central word in a Chinese compound.

The study is still not enough to compare only the lexical structure in Korean and Chinese from the perspective of compound words. To compare lexical structure in Korean and Chinese in further details, it should also include other types of words, namely the derivatives in Chinese, due to the vast difference between Chinese and Korean vocabulary classification systems. The relationship between compound words and single-morpheme words, and also between the derivatives and complex compounds should be explored.

\section{REFERENCES}

Aronoff, M., \& Fudeman, K. (2010). What is Morphology?. United Kingdom: Wiley-Blackwell

Bloomfield, L. (1933). Language. New York: Holt, Rinehart and Winston. 
Ge, Ben Yi. (葛本仪). (1988). 论合成词素 [morphemes of compound words]. 山东大学学报：哲学社会科 学版 [Journal of Shandong University (Philosophy and Social Sciences)], 87-92.

Ham, Hee Jin. (함희진). (2007). 합성 동사와 합성형 용사의 어휘사적 연구 [The Historical study on Korean Compound verb and Compound adjective]. Journal of Korean Culture, 8, 157-192.

Hwang, Hwa-Sang (황화상). (2001). 국어 형태 단위의 의미와 단어 형성 [Meaning of Morphological Units and Word Formation in Korean]. Seoul: Worin (月印).

Peng, Ying Xi. (彭迎喜). (1995). 几种新拟设立的汉语 复合词结构类型[Several kinds of structure types of Chinese compound words which are planned to be set up]. Journal of Tsinghua University, 34-36.

Qin, Rao. (饶勤). (1993). 从句法结构看复合词中的一种 新的构词方式一一连动式构词 [An analysis of a new word-formation of the compound words in view of syntactical structure -- serial verb construction]. Chinese Language Learning, 15-16.

Shi, Ding Xu. (石定栩) (2007). 向心结构与离心结构 新探 [Endocentric construction and exocentric construction]. 外语教学与研究 [Foreign language teaching and research], 276-284.

Sweet, H. (2014). A New English Grammar, Logical and Historical. United Kingdom: Cambridge University Press

Zhu, De Xi. (朱德熙). (1984). 矢于向心结构的定义 [On definitions of endocentric structure]. 中国语文 [Studies of the Chinese Language](6), 401. 